\title{
An Environmental Learning Support System Incorporating the Life Cycle Concept
}

\author{
Akira Shirato*, Kayoko Yamamoto \\ Graduate School of Informatics and Engineering, University of Electro-Communications, Tokyo, Japan \\ Email: *s2030053@edu.cc.uec.ac.jp, kayoko.yamamoto@uec.ac.jp
}

How to cite this paper: Shirato, A. and Yamamoto, K. (2020) An Environmental Learning Support System Incorporating the Life Cycle Concept. Journal of Environmental Protection, 11, 491-508.

https://doi.org/10.4236/jep.2020.116029

Received: June 1, 2020

Accepted: June 25, 2020

Published: June 28, 2020

Copyright $\odot 2020$ by author(s) and Scientific Research Publishing Inc. This work is licensed under the Creative Commons Attribution International License (CC BY 4.0).

http://creativecommons.org/licenses/by/4.0/

(c) (i) Open Access

\begin{abstract}
The need for environmental education, which incorporates the life cycle concept into the learning program, will become increasingly greater all over the world. In the present study, an e-learning system, which is made up of 3 parts including text-based learning materials, quizzes to review the content of the learning materials and $\mathrm{CO}_{2}$ emission simulation, was designed and developed with the purpose of supporting environmental learning. Targeting a wide range of people, the operation period of this system was 1 month. Based on the results of questionnaire survey for users, it was evident that the quiz function and the simulation function of $\mathrm{CO}_{2}$ emission contributed to the efficiency in environmental learning, and the format of the e-learning system was effective and helpful for environmental learning. Additionally, with the users' awareness related to environmental conservation before and after using the system, significant changes in awareness were seen in areas such as behavioral intention, sense of urgency and sense of connection. Furthermore, as it was revealed that $62 \%$ of the total access numbers were from mobile devices, it was effective to prepare an interface optimized for mobile devices enabling users to use the system from their smartphones and tablet PCs.
\end{abstract}

\section{Keywords}

Environmental Learning, Life Cycle Assessment (LCA), Life Cycle Concept, Environmental Education, Sustainable Development Goals (SDGs), E-Learning System

\section{Introduction}

In recent years, current social and economic systems involving mass production, mass consumption and mass disposal have been regarded as an issue due to the escalation of global environmental problems. The United Nations (UN) presented sustainable development goals (SDGs) in 2015, and various activities concerning 
global environmental conservation have been implemented towards achieving the goals by 2030 (Institute of Life Cycle Assessment, Japan, 2013) [1]. It is also required of all of us, as consumers, to behave in an environmentally responsible manner towards the realization of a sustainable society. However, many of us who highly use opaque technologies and systems in this modern society are not fully aware of the close connection between our daily consumption and production activities and the natural environment that supports such activities. Under these current circumstances, the need for environmental education to learn about the environment will become increasingly greater.

Additionally, according to Ilgin et al. (2010) [2] and United State Environmental Protection Agency (EPA, 2012) [3], life cycle assessment (LCA, also known as life cycle analysis) is a methodology for assessing environmental impacts associated with all the stages of the life cycle of a commercial product, process or service. For example, in the case of a manufactured product, environmental impacts are assessed from raw material extraction and processing (cradle), through the product's manufacture, distribution and use, to the recycling or final disposal of the materials to compose it (grave). Studies on LCA involve a thorough inventory of the energy and materials that are required across the industry value chain of the product, process or service, and calculate the corresponding emissions to the environment. Thus, LCA assesses cumulative potential environmental impacts, and it aims to document and improve the overall environmental profile of the product.

Regarding the environmental education scene, efforts to incorporate the life cycle concept into the learning program have been occasionally seen (Hondo, 2008) [4]. The significance of incorporating the life cycle concept in environmental learning is that, first, learners can more easily make specific connections between daily consumer activities and environmental problems, and recognize that their own behavior choices are deeply involved with global environmental problems, by learning about the life cycle concept. Second, learners can quantitatively compare and determine the environmental impact, which tends to be qualitatively assessed, by learning about the direct assessment and analysis method of the environmental impact called the LCA.

Based on the above, the present study aims to develop an e-learning system to support environmental learning based on the life cycle concept. The purpose of this system is to improve the life cycle thinking (LCT) ability of users by means of comprehensive environmental learning about program starting from knowledge acquisition to applied exercises which are designed and developed (Sections 3 and 4). Users of various age groups will use the system (Section 5); it will be assessed by means of a questionnaire survey for users and access analyses; issues will be extracted; and solutions will be summarized (Section 6).

\section{Related Work}

The present study is related to 3 research fields including 1 ) the studies related to 
the life cycle concept in environmental education/learning, 2) the studies related to environmental education/learning support system, and 3) the studies related to the outcome of environmental education/learning that introduced the life cycle concept. For 1) the studies related to the life cycle concept in environmental education/learning, Hondo et al. (2008) [4] mentioned the importance of environmental education and the effectiveness of the life cycle concept in designing environmental conservation. Saarinen et al. (2012) [5] proposed a food-related communication tool for sustainable education in the upper levels of elementary schools, focusing on the LCA in a range of lunches. Tsuchiya (2013) [6] introduced the concept of sustainability and LCA in the first term of secondary education in the United Kingdom (UK). Curran (2015) [7] published a handbook which concisely and clearly presented the various aspects of LCA in order to help students better understand the subject. Ramos et al. (2015) [8] addressed the experiences from the implementation of sustainable development including LCA in higher education institutions. Uchida et al. (2017) [9] compared life cycle $\mathrm{CO}_{2}$ between PET bottle and drink carton at a Japanese university. Kikuchi et al. (2017) [10] applied quantitative assessment methods into the chemical risk management at Japanese universities with actual data on site. Mori et al. (2018) [11] developed and tested the standard (connection) for measuring learners' awareness of how their "daily life and environmental problems are connected" which was developed through environmental education based on the life cycle concept. Goodall (2018) [12] developed environmental education adopting LCA in the curriculums of elementary and junior high schools.

For 2) the studies related to environmental education/learning support system, Poudelet et al. (2012) [13] addressed the issue by proposing a business process reengineering (BPR) methodology that can be used to develop suitable decision-support systems (DSS). Hirayama et al. (2015) [14] developed an e-learning system for environmental studies that applied the life cycle concept. Santos et al. (2014) [15] provided web-based educational systems with personalised support for the e-learning life cycle. Uehara et al. (2017) [16] suggested an information provision software with the subject of plastic bags and personal shopping bags as a specific environmental information provision method to improve LCT abilities.

For 3) the studies related to the outcome of environmental education/learning that introduced the life cycle concept, Nakamura et al. (2008) [17] conducted a quantitative analysis using the conjoint analysis concerning the effect of environmental education materials that were based on the life cycle concept in Japan. Baboulet et al. (2010) [18] applied hybrid LCA methods combining input-output analysis and process analysis to the task of planning for a sustainable campus to evaluate the environmental performance at an Australian university. Nakajima et al. (2011) [19] implemented an environmental education program using the LCA software, and verified the effects of changes in environmental awareness and environment-conscious behavior of students as well as their mechanisms at 
a Japanese high school. Imoto et al. (2012) [20] analyzed the consciousness alteration of students before and after practical work on a farm from the viewpoint of LCA at a Japanese university. Foo (2013) [21] revealed the role of environmental higher education contributing to the sustainable development including LCA at Malaysian universities. Seo (2015) [22] developed and verified a teaching materials by using LCT for home economics at elementary and junior high schools in Japan. Ueno et al. (2015) [23] analyzed the environmentally related content of textbooks in home economics of Japan, extracting words related to the environment and focusing on the LCA and LCT.

In this way, there are currently only a few support systems for environmental education/learning developed based on the life cycle concept. Among 2) the studies related to environmental education/learning support system, the purposes of Hirayama et al. (2015) [14] and Uehara et al. (2017) [16] are similar to the one of the present study. However, the system developed by Hirayama et al. (2015) [14] has issues such as the need to download a program file when using the system, the utilization of the program operating environment being limited to Windows OS, and the operation subjects of the system being limited to junior high and high school students. Therefore, as the subjects for Hirayama et al. (2015) [14] were limited, this system could not effectively and efficiently support environmental learning. Additionally, the subjects used in environmental learning were limited to "Inside the bags" for Hirayama et al. (2015) [14] and "Plastic bags and personal shopping bags" for Uehara et al. (2017) [16].

In comparison with the preceding studies listed above, the first point of originality in the present study is that an e-learning system that can be used for online environmental learning based on the life cycle concept is developed. The second point of originality is that system-related limitations are lessened by extending the operating environment to OSs other than Windows OS and developing a system that can be used from various devices. Third, the system can be used by a wide range of age groups, as the subject for environmental learning is "drinking water", which is something familiar to everyone.

\section{System Design}

\subsection{System Characteristics}

As shown in Figure 1, the system in the present study is an e-learning system made up of 3 parts including text-based learning materials, quizzes to review the content of the learning materials, and $\mathrm{CO}_{2}$ emission simulation. In addition to supporting environmental learning, the purpose of the system is to improve LCT ability and heighten the awareness of environmental conservation by having users learn about global warming, LCA and life cycle concept.

First, users will learn about global warming, LCA and life cycle concept by text-based learning materials provided by the system. Furthermore, they can effectively review what they learned by solving the problems in the quiz related to the content of the text-based learning materials. Additionally, the function that 


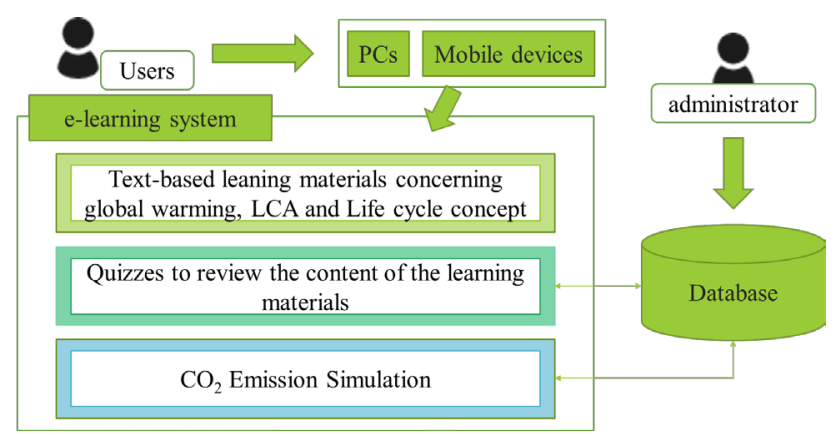

Figure 1. Design of e-learning system in the present study.

estimates the amount of $\mathrm{CO}_{2}$ emission in everyday life enables users to conduct practical exercises based on what they learned. Therefore, as the system has a framework that allows users to systematically learn about the life cycle concept and efficiently supports their environmental learning, they can effectively gain an understanding of the content provided by the system in the preset study.

\subsection{Target Devices}

In recent years, smartphones and tablet PCs are widely used as mobile devices. As this is an e-learning system using the internet, it is expected to be accessed from mobile devices such as smartphones and tablet PCs in addition to PCs. Though the interface may differ according to the device used, the same functions can be used from any device.

\subsection{Operation Environment of the System Developed in the Preset Study}

The system developed in the preset study operates using 2 servers: the Web server and the database server. Heroku, which is a PaaS provided by Salesforce.com, inc., is used for both the Web server and the database server. The e-learning system developed in the present study is implemented using PHP, JavaScript and HTML.

\subsection{Design of Each System}

\subsubsection{Learning Material}

The necessity of environmental education is explained from the viewpoint of activities and trends concerning SDGs in recent years. Next, a detailed explanation for the specific process of LCA is provided, using plastic as an example, to help users fully understand the life cycle concept. The environmental impact of plastic bags is also used as an example in introducing analysis cases of $\mathrm{CO}_{2}$ emission from the viewpoint of life cycle concept. Additionally, product analyses using LCA in the cases of NH Foods Ltd. [24] are provided as practical examples to introduce corporate activities that are closely related to the daily life of users.

\subsubsection{Quiz}

After learning about the life cycle concept, users will take a quiz (mini test) to 
review what they learned. In the environmental learning programs proposed by Hirayama et al. (2015) [14] and Uehara et al. (2017) [16], the only exercise conducted after learning about the life cycle concept was the estimation of $\mathrm{CO}_{2}$ emission. However, this system is designed to effectively assist users in their learning by adding quizzes as an exercise.

\subsection{3. $\mathrm{CO}_{2}$ Emission Simulation}

As this system is expected to be widely used by the public, it is desirable for users to easily operate the system in a browser using the internet without having to install a special software. In the present study, the system itself is uploaded to an online server and developed as an e-learning system. By doing so, there are no limitations related to the system and the design enables the estimation of $\mathrm{CO}_{2}$ emission to be easily conducted.

Additionally, the subject should be something familiar to many in order to improve users' LCT ability and promote behavior change in their daily life. Therefore, with "drinking water" as the chosen subject for the present study, the amount of $\mathrm{CO}_{2}$ emission according to the utilization form of drinking water for each user is estimated and the results are displayed in graph form, using the simulation function described in the next section.

\section{System Development}

\subsection{Frontend of the System}

The original functions for users mentioned in detail below are implemented in the present study.

\subsubsection{Viewing Function of the Learning Material}

Users can go to the page for the viewing function of learning materials by clicking the "What are SDGs?" and "learn" in the menu of the top page. By using this function, users can learn about global warming, LCA and life cycle concept. An example page for this function is shown in Figure 2.

\subsubsection{Quiz Function}

Users can go to the page for the quiz function by clicking on "quiz" in the menu of the top page. On this page, quizzes, which are related to the content users learned using the viewing function of learning materials, are prepared, and they can effectively use this function to review what they have learned. An example page for this function is shown in Figure 3. In Figure 3, the first quiz is asked to make correct/incorrect determination, and the second one is requested to rearrange the processes of LCA targeting plastics.

\subsubsection{Simulation Function of $\mathrm{CO}_{2}$ Emission}

Users can go to the page for the simulation function of $\mathrm{CO}_{2}$ emission by clicking on "simulation" in the menu of the top page. On this page, the amount of $\mathrm{CO}_{2}$ emission is simulated based on the utilization form of drinking water for each user and displayed in graph form. This enables users to have a more practical 
exercise in order to utilize the knowledge they learned and reviewed in their daily life, using the viewing function of learning materials and the quiz function. The page for this function is shown in Figure 4.

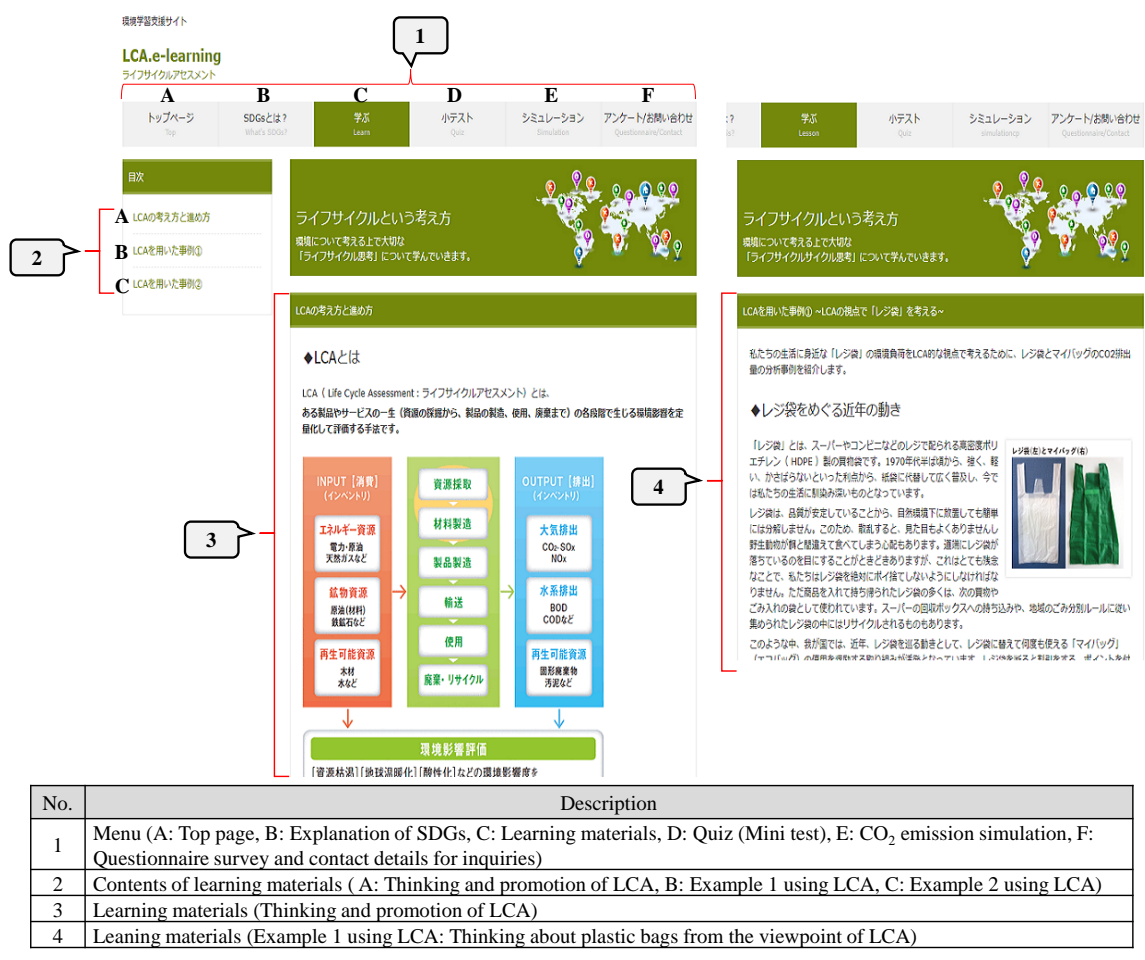

Figure 2. An example page for viewing function of learning materials.

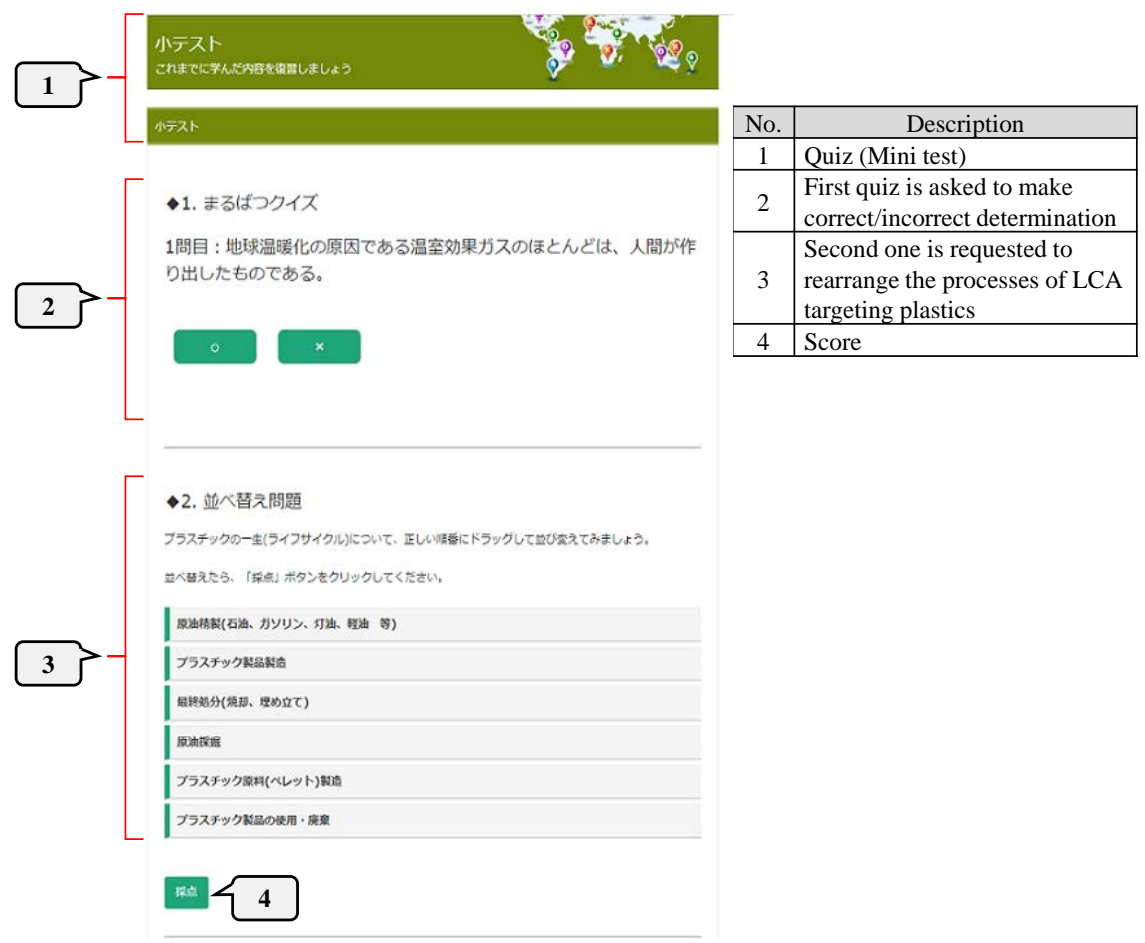

Figure 3. An exampe page for quize function. 


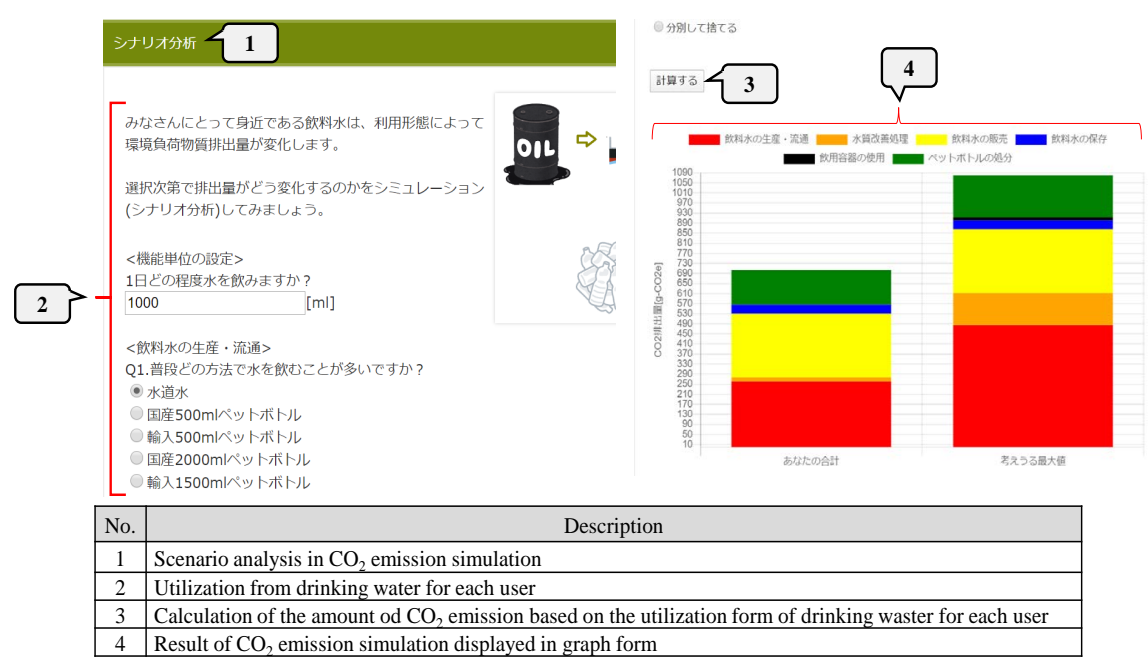

Figure 4. Page for simulation function of $\mathrm{CO}_{2}$ emission.

\subsection{Backend of the System}

\subsubsection{Processing Related to the Learning Materials}

The process of storing the answers and scores of users obtained using the quiz function into the database, and returning the graded results back to them is conducted. By this process, users can understand their amount of knowledge and degrees of comprehension related to global warming, LCA and life cycle concept.

\subsubsection{Processing Related to the Simulation of $\mathrm{CO}_{2}$ Emission}

The process of storing the values entered by users using the simulation function of $\mathrm{CO}_{2}$ emission into the database, calculating the values to display them in graph form, and returning the results to them is conducted.

\subsection{System Interface}

A responsive design is selected as the interface of this system, and the screen is optimized according to the display size of the users' device. While 2 types of interfaces for PCs and mobile devices are prepared, the same functions can be used from any device.

\section{Operation}

\subsection{LCA Data}

Specific data concerning LCA assessment is required to implement the simulation function of $\mathrm{CO}_{2}$ emission of this system. As shown in Table 1, the present study used the estimated data of $\mathrm{CO}_{2}$ emission for each utilization form of drinking water provided by Miki et al. (2010) [25]. According to Miki et al. (2010) [25], one characteristic of drinking water is that the change in the assessment value of LCA (amount of $\mathrm{CO}_{2}$ emission) significantly depends on the utilization conditions of consumers. 
Table 1. Data used to estimate the amount of $\mathrm{CO}_{2}$ emission according to the utilization conditions.

\begin{tabular}{|c|c|c|}
\hline $\begin{array}{l}\text { Evaluation stages } \\
\text { of drinking water }\end{array}$ & Choices & $\begin{array}{l}\text { Amount of } \mathrm{CO}_{2} \text { emission }\left[\mathrm{g}-\mathrm{CO}_{2} \mathrm{e}\right] \\
\text { (drinking water } x \text { consumed } \mathrm{mL} \text { ) }\end{array}$ \\
\hline \multirow{5}{*}{$\begin{array}{l}\text { Production and } \\
\text { distribution of } \\
\text { drinking water }\end{array}$} & Tap water supply & $0.000288 x$ \\
\hline & Domestic $500 \mathrm{~mL}$ plastic bottle & $0.261 x$ \\
\hline & Imported $500 \mathrm{~mL}$ plastic bottle & $0.484 x$ \\
\hline & Domestic $2000 \mathrm{~mL}$ plastic bottle & $0.176 x$ \\
\hline & Imported $1500 \mathrm{~mL}$ plastic bottle & $0.410 x$ \\
\hline \multirow{4}{*}{$\begin{array}{l}\text { Water quality } \\
\text { improvement } \\
\text { treatment }\end{array}$} & No treatment & 0 \\
\hline & Boiled & $0.128 x$ \\
\hline & Filtered water & $0.000683 x$ \\
\hline & Chilled water & $0.0154 x$ \\
\hline \multirow{3}{*}{$\begin{array}{c}\text { Sale of } \\
\text { drinking water }\end{array}$} & Sold at room temperature & $0.0435 x$ \\
\hline & Sold in a refrigerator & $0.164 x$ \\
\hline & Sold in a vending machine & $0.254 x$ \\
\hline \multirow{2}{*}{$\begin{array}{c}\text { Storage of } \\
\text { drinking water }\end{array}$} & Not stored in a refrigerator & 0 \\
\hline & Stored in a refrigerator & $0.0350 x$ \\
\hline \multirow{4}{*}{$\begin{array}{c}\text { Utilization of } \\
\text { drinking containers }\end{array}$} & No container & $0.000515 x$ \\
\hline & Glass & 4.08 \\
\hline & Water flask & 12.2 \\
\hline & Plastic bottle & 0 \\
\hline \multirow{10}{*}{$\begin{array}{c}\text { Disposal of } \\
\text { plastic bottles }\end{array}$} & No purchase or use & 0 \\
\hline & Multiple-use & 1.80 \\
\hline & \multirow{4}{*}{ Burnable waste disposal } & Domestic $500 \mathrm{~mL}: 0.167 x$ \\
\hline & & Imported $500 \mathrm{~mL}: 0.138 x$ \\
\hline & & Domestic 2000 mL: $0.0865 x$ \\
\hline & & Imported $1500 \mathrm{~mL}: 0.0632 X$ \\
\hline & \multirow{4}{*}{ Sorted disposal } & Domestic $500 \mathrm{~mL}:-0.0376 x$ \\
\hline & & Imported $500 \mathrm{~mL}:-0.0303 x$ \\
\hline & & Domestic $2000 \mathrm{~mL}:-0.0177 x$ \\
\hline & & Imported $1500 \mathrm{~mL}:-0.0120 \mathrm{X}$ \\
\hline
\end{tabular}

\subsection{Operation}

\subsubsection{Operation Overview}

The operation of this system was implemented for 1 month. Utilization was promoted through the website, Twitter and Facebook account of the authors' lab. The system can be used simply by accessing the website and does not require users to register. Users will first learn about LCA using the viewing function of learning materials. Next, they will review what they have learned using the quiz function. Lastly, using the simulation function of $\mathrm{CO}_{2}$ emission, users can practically learn about LCA in an exercise style by estimating the amount of $\mathrm{CO}_{2}$ emission in their daily life with drinking water as an example. 


\subsubsection{Operation Results}

It was revealed from the access log analysis results, which is described in detail in the next section, that there were 111 active users of this system. Among these users, the breakdown of users who responded to the questionnaire survey after using the system is shown in Table 2. There were a total of 58 users including 33 men and 25 women. Regarding age groups, the highest percentage for both men and women were those in their 20 s, making up $43 \%$ of the total. The next highest percentages were $17 \%$ for those in their 40 s and $12 \%$ for those in their 70 s. In this way, it is evident that there are users from a wide range of age groups. Therefore, it can be said that it was appropriate to select "drinking water", which is a subject familiar to everyone, for the environmental learning in the present study.

\section{Evaluation}

After the operation, a questionnaire survey for users and an access log analysis were conducted to evaluate this system.

\subsection{Evaluations Based on the Questionnaire Survey}

\subsubsection{Overview of the Questionnaire Survey}

According to the purpose of the present study, a questionnaire survey was conducted concerning 3 points including 1) the evaluation related to the system utilization, 2) the evaluation related to each function and the system as a whole, and 3) the evaluation focused on changes in awareness before and after using the system. This survey was conducted on the website 1 week after the start of the operation.

\subsubsection{Evaluation Related to the System Utilization}

1) Evaluation of the compatibility with the internet utilization situation

Regarding the frequency of internet use, $95 \%$ answered "every day" or "a few times a week". Therefore, it was effective to allow easy access for users by releasing this system as an online e-learning system, as most of them use the internet on a daily basis. Additionally, regarding the devices used to access the system, $28 \%$ answered PCs while $72 \%$ answered smartphones and tablet PCs. Therefore, it was effective to design the system with a screen exclusively for mobile devices.

2) Evaluation focused on the learning situation on LCA

Regarding the recognition of LCA, $40 \%$ answered "I knew" while $60 \%$ answer "I didn't know". This shows that over half of the users learned about LCA for the first time using the system. Additionally, regarding environmental learning experiences, $72 \%$ answered "I have experience" while $28 \%$ answered "I have no experience". The former users mainly experienced it through school programs, and had little experience with voluntary learning using an e-learning system similar to that of the present study (13 users, 22\%). Therefore, it was evident that many users had experience in environmental learning, and the ratio of those who had learning experience using an e-learning system was low. 
Table 2. Breakdown of users (respondents to the questionnaire survey).

\begin{tabular}{ccccccccc}
\hline The age group of users & 10 & 20 & 30 & 40 & 50 & 60 & 70 & Total \\
\hline Number of users (people) & 4 & 25 & 4 & 10 & 5 & 3 & 7 & 58 \\
\hline
\end{tabular}

\subsubsection{Evaluation Related to Each Function and the System as a Whole}

The evaluation results for each function and the system as a whole are shown in Figure 5. Among the 3 functions in this system, the evaluation focused on the quiz function and the simulation function of $\mathrm{CO}_{2}$ emission used as an exercise on the users' own initiative. Regarding the efficiency of these two functions, those who answered "I think so" or "I somewhat think so" were $92 \%$ for the former and $96 \%$ for the latter. Therefore, it was clear that these two functions efficiently supported the learning experience of users.

Next, the evaluation focused on the system as a whole. Regarding the usefulness of the system in voluntary environmental learning and school education, those who answered "I think so" and "I somewhat think so" were 95\% for the former and $93 \%$ for the latter. However, those who answered "I think so" were $38 \%$ for voluntary environmental learning and $52 \%$ for school education. This shows that the usefulness of the system in school education rather than voluntary environmental learning is strongly anticipated.

Regarding the visibility of the system interface, $90 \%$ answered "I think so" or "I somewhat think so", while $10 \%$ answered "I don't think so". This was due to the fact that $72 \%$ of users accessed the system from their smartphones or tablet PCs, causing some of them to feel that it was hard to see on a small screen.

\subsubsection{Evaluation Focused on the Changes in Awareness before and after Using the System}

The changes in awareness of environmental issues and environmental conservation before and after using the system were measured and evaluated. The results are shown in Table 3. These question items were set in reference to the experiment conducted by Uehara (2017) [16] with junior high and high school students and adults as subjects. There were 7 question items including behavioral intention and a sense of effectiveness, responsibility, burden and feasibility related to environmental conservation, and a sense of urgency related to environmental problems, as well as a sense of connection related to interests in environmental problems based on the life cycle concept.

The results of responses for each question item are summarized below.

1) Behavioral intention related to environmental conservation

For the 4 question items concerning behavioral intention, approximately half the respondents answered "I strongly agree now" to all the questions, and over approximately $80 \%$ answered either "I strongly agree now" or "I somewhat agree now", indicating a significant difference in behavioral intention before and after using the system.

2) Sense of effectiveness related to environmental conservation 


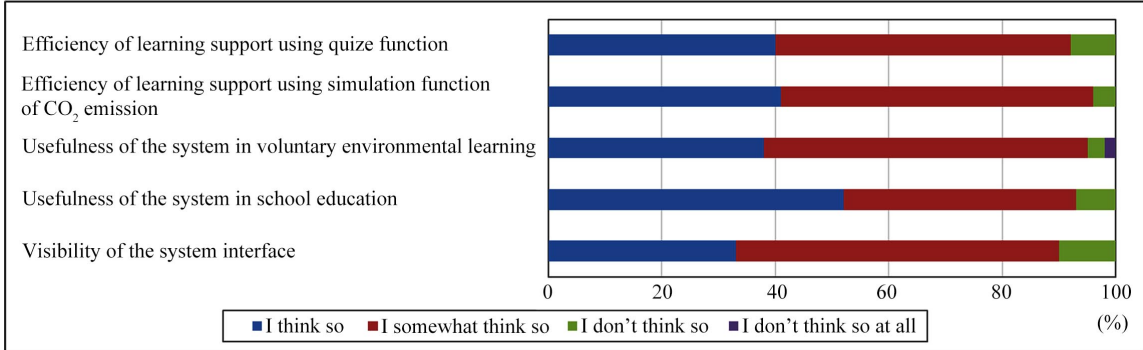

Figure 5. Evaluation results for each function and the system as a whole.

Table 3. Results in changes of awareness before and after using the system.

\begin{tabular}{|c|c|c|c|c|c|}
\hline Question items & $\begin{array}{l}\text { I strongly } \\
\text { agree now }\end{array}$ & $\begin{array}{l}\text { I somewhat } \\
\text { agree now }\end{array}$ & $\begin{array}{l}\text { No } \\
\text { change }\end{array}$ & $\begin{array}{l}\text { I somewhat } \\
\text { disagree now }\end{array}$ & $\begin{array}{l}\text { I disagree } \\
\text { now }\end{array}$ \\
\hline \multicolumn{6}{|l|}{ 1) Behavioral intention related to environmental conservation } \\
\hline We wish to recycle and separate wastes & 48.3 & 31.0 & 19.0 & 1.7 & 0.0 \\
\hline We wish to use more environmentally friendly products & 43.1 & 36.2 & 19.0 & 1.7 & 0.0 \\
\hline $\begin{array}{l}\text { We wish to carefully use what we still use over a long period as much as } \\
\text { possible }\end{array}$ & 44.9 & 37.9 & 13.8 & 3.4 & 0.0 \\
\hline We don't wish to buy and wish to refuse unnecessary items & 50.0 & 29.3 & 19.0 & 1.7 & 0.0 \\
\hline \multicolumn{6}{|l|}{ 2) Sense of effectiveness related to environmental conservation } \\
\hline A single individual daily behavior is effective to prevent global warming & 37.9 & 41.4 & 19.0 & 1.7 & 0.0 \\
\hline $\begin{array}{l}\text { If we use daily necessaries over a long period as much as } \\
\text { possible, we can reduce } \mathrm{CO}_{2} \text { emission }\end{array}$ & 46.6 & 39.7 & 12.1 & 1.6 & 0.0 \\
\hline If we all cooperate little by little, we can avoid global warming & 17.2 & 56.9 & 19.0 & 6.9 & 0.0 \\
\hline We can reduce $\mathrm{CO}_{2}$ emission with individual efforts & 22.4 & 58.7 & 15.5 & 3.4 & 0.0 \\
\hline \multicolumn{6}{|l|}{ 3) Sense of responsibility related to environmental conservation } \\
\hline We have to amend our present convenient life & 10.3 & 62.1 & 25.9 & 1.7 & 0.0 \\
\hline Huge amount of $\mathrm{CO}_{2}$ is emitted due to our behavior & 20.7 & 60.4 & 3.4 & 15.5 & 0.0 \\
\hline We are also the cause of global warming & 36.2 & 41.4 & 19.0 & 3.4 & 0.0 \\
\hline \multicolumn{6}{|l|}{ 4) Sense of burden related to environmental conservation } \\
\hline It is not so difficult to reduce $\mathrm{CO}_{2}$ emission in our daily life & 8.6 & 36.2 & 41.4 & 13.8 & 0.0 \\
\hline \multicolumn{6}{|l|}{ 5) Sense of feasibility related to environmental conservation } \\
\hline $\begin{array}{l}\text { We have many opportunities and methods to reduce } \mathrm{CO}_{2} \\
\text { mission in our daily life }\end{array}$ & 15.6 & 53.4 & 27.6 & 1.7 & 1.7 \\
\hline \multicolumn{6}{|l|}{ 6) Sense of urgency related to environmental problems } \\
\hline We have to prevent global warming & 51.8 & 31.0 & 13.8 & 3.4 & 0.0 \\
\hline Global warming is in a serious state & 60.4 & 24.1 & 15.5 & 0.0 & 0.0 \\
\hline \multicolumn{6}{|c|}{ 7) Sense of connection related to interests in environmental problems based on the life cycle concept } \\
\hline $\begin{array}{l}\mathrm{CO}_{2} \text { emission from factories and power stations connects to familiar goods } \\
\text { in our daily life }\end{array}$ & 46.6 & 39.7 & 13.7 & 0.0 & 0.0 \\
\hline Our behavior connects to various activities in society & 34.5 & 51.7 & 12.1 & 1.7 & 0.0 \\
\hline $\begin{array}{l}\text { Familiar goods such as PET bottles go through various places before } \\
\text { reaching us }\end{array}$ & 51.7 & 32.8 & 13.8 & 1.7 & 0.0 \\
\hline $\begin{array}{l}\mathrm{CO}_{2} \text { is generated in various processes such as production and } \\
\text { transportation of resources and manufacturing products due to our daily } \\
\text { behavior }\end{array}$ & 44.8 & 41.4 & 12.1 & 1.7 & 0.0 \\
\hline
\end{tabular}


For the 4 question items concerning the sense of effectiveness, over $70 \%$ answered either "I strongly agree now" or "I somewhat agree now". However, for the 2 items including "If we all cooperate little by little, we can avoid global warming" and "We can reduce $\mathrm{CO}_{2}$ emission with individual efforts", the percentage of "I somewhat agree now" was extremely higher than "I strongly agree now". Therefore, though not as much as behavioral intention, there was a difference in the sense of effectiveness before and after using the system.

3) Sense of responsibility related to environmental conservation

For the 3 question items concerning the sense of responsibility, over $70 \%$ answered "I strongly agree now" and "I somewhat agree now". However, for all 3 questions, the percentage of "I somewhat agree now" was higher than "I strongly agree now". Therefore, the difference in the sense of responsibility was not so significant before and after using the system.

4) Sense of burden related to environmental conservation

For the question concerning the sense of burden, the highest percentage of answers with $41 \%$ was "no change". Additionally, $14 \%$ answered "I somewhat disagree now". Therefore, half of the respondents demonstrated changes in awareness, while the other half hardly demonstrated any changes on the sense of burden before and after using the system.

5) Sense of feasibility related to environmental conservation

For the question concerning the sense of feasibility, the highest percentage of answers with 53\% was "I somewhat agree now" and 28\% answered "no change". Therefore, there was little difference in the sense of feasibility before and after using the system.

6) Sense of urgency related to environmental problems

For the 2 question items concerning the sense of urgency, the highest percentage of answers was "I strongly agree now", and over $80 \%$ answered either "I strongly agree now" or "I somewhat agree now". This shows that there was a great difference in the sense of urgency before and after using the system.

7) Sense of connection related to interests in environmental problems based on the life cycle concept

For the 4 question items concerning the sense of connection, over approximately $85 \%$ answered "I strongly agree now" or "I somewhat agree now". Additionally, about half answered "I strongly agree now" for the 3 question items except for "Our behavior connects to various activities in society". Therefore, there was a great difference in the sense of connection before and after using the system.

To summarize the above, the system was able to heighten the respondents' awareness in areas such as behavioral intention related to environmental conservation, the sense of urgency related to environmental problems, and the sense of connection related to interests in environmental problems based on the life cycle concept. On the other hand, the awareness in areas such as the sense of effectiveness, responsibility and feasibility related to environmental conservation were marginally heightened, and the difference in awareness for the sense of bur- 
den related to environmental conservation was not desirable.

\subsection{Evaluation Based on the Access Analysis}

In the present study, an access log analysis was conducted using the log data of users during the operation period. The analysis is conducted using Google Analytics API which is a web access analysis service provided by Google. The access $\log$ can be obtained by writing the API into the program of each page of the website.

The total number of sessions in this system is 97 . For the devices used as an access method, $38 \%$ were PCs, $58 \%$ were smartphones and $4 \%$ were tablet PCs. This shows that the same functions can be used regardless of the devices used as the access method, and the system design with 2 types of interfaces for both PCs and mobile devices depending on the size of the display was effective. Additionally, in contrast with the systems developed by Hirayama et al. (2015) [14] and Uehara et al. (2017) [16] that could not be accessed from mobile devices such as smartphones and tablet PCs, the system was effective in enabling access from smartphones and tablet PCs taking into consideration the increase in the use of mobile devices.

The top 10 pages with the highest number of visits are shown in Table 4. This table reveals that the pages for the viewing function of learning materials, the quiz function, and the simulation function of $\mathrm{CO}_{2}$ emission are used the most. Therefore, it can be said that the system utilization is in line with the purpose of the present study which is to support the environmental learning of users. However, the number of visits beyond the 2nd page for the viewing function of learning materials is low compared to the ones of other 2 function. This may be due to users not accessing the 2nd page onward as they already had some knowledge of LCA before using the system, or because some of them moved onto the page for the quiz function without viewing all of the learning materials.

Table 4. Number of visits per page (Top 10).

\begin{tabular}{llll}
\hline Rank & Page name & Page visits & Percentage (\%) \\
\hline 1 & Top page (for mobile devices) & 60 & 21.3 \\
2 & Page on SDGs & 34 & 12.1 \\
3 & Page for viewing function of learning materials (Page 1) & 28 & 9.9 \\
4 & Page for simulation function of $\mathrm{CO}_{2}$ emission & 28 & 9.9 \\
5 & Page for quiz function & 22 & 7.8 \\
6 & Page for questionnaire survey & 24 & 8.5 \\
7 & Top page (for PCs) & 22 & 7.8 \\
8 & Page for viewing function of learning materials (Page 2) & 16 & 5.7 \\
9 & Top page (different link) & 13 & 4.6 \\
10 & Page for viewing function of learning materials (Page 3) & 13 & 4.6 \\
\hline
\end{tabular}




\subsection{Extraction of Improvement Measures}

Measures for improvement related to the system extracted based on the results of the questionnaire survey and the access log analysis are summarized below.

1) Review of the content of learning materials

With the expectation that a wide range of age groups will use the system, the writing style should be simple and the main points should be concise, instead of including technical and detailed content. Additionally, the content should be easy to understand for users that have just started their environmental learning.

2) Implementation of the storing function of quiz results

A more effective manner of review can be anticipated, if the quiz results can be stored in the system, and users can review their previous results.

3) Implementation of the display function of comments according to the simulation results

The displaying function of comments to indicate whether the amount of $\mathrm{CO}_{2}$ emission estimated by users is appropriate or not, and the process in which the amount of $\mathrm{CO}_{2}$ emission was incorrect, if the estimation was too high should be implemented. This can encourage users to be conscientious on their specific behavior to reduce the amount of $\mathrm{CO}_{2}$ emission.

\section{Conclusions}

In the present study, a system was designed and developed (Sections 3 and 4); operation was conducted (Section 5), and evaluations as well as the extraction of improvement measures were performed (Section 6). The present study can be summarized in the following 3 points.

1) An e-learning system, which is made up of 3 parts including text-based learning materials, quizzes to review the content of the learning materials, and $\mathrm{CO}_{2}$ emission simulation, was designed and developed with the purpose of supporting environmental learning. Users that were expected to be from a wide range of age groups were recruited, and the system was operated and evaluated.

2) The operation period of this system was 1 month. Based on the results of questionnaire survey for users, it was evident that the quiz function and the simulation function of $\mathrm{CO}_{2}$ emission contributed to the efficiency in environmental learning, and the format of the e-learning system was effective and helpful for environmental learning. Additionally, with the users' awareness related to environmental conservation before and after using the system, significant changes in awareness were seen in areas such as behavioral intention, sense of urgency and sense of connection. On the other hand, there were no major changes in awareness concerning the sense of effectiveness, responsibility and feasibility, and there was also no desirable change for a sense of burden.

3) According to the access analysis of the log data during the operation period, it was revealed that $62 \%$ of the total access numbers were from mobile devices. Therefore, it was effective to prepare an interface optimized for mobile devices enabling users to use the system from their smartphones and tablet PCs. 
As for future research projects, an improvement of the system according to the outcome of Section 6.3 as well as the enhancement of utilization significance by increasing the number of users can be mentioned.

\section{Acknowledgements}

In the operation of the environmental learning support system incorporating the life cycle concept and the web questionnaires of the present study, enormous cooperation was received from those in all parts of Japan. We would like to take this opportunity to gratefully acknowledge them.

\section{Conflicts of Interest}

The authors declare no conflicts of interest regarding the publication of this paper.

\section{References}

[1] The Institute of Life Cycle Assessment, Japan (2013) Recommendation of Environmental Education Based on Life Cycle Concept. 10-48.

[2] Ilgin, M.A. and Gupta, S.M. (2010) Environmentally Conscious Manufacturing and Product Recovery (ECMPRO): A Review of the State of the Art. Journal of Environmental Management, 91, 563-591. https://doi.org/10.1016/j.jenvman.2009.09.037

[3] United Sates Environmental Protection Agency (2012) Design for the Environment Life-Cycle Assessments.

https://www.epa.gov/saferchoice/design-environment-life-cycle-assessments

[4] Hondo, H., Hirayama, Y., Nakajima, K., Yamada, S. and Fukuhara, I. (2008) Use of Life Cycle Thinking in Environmental Education: Visualization and Recovery of the Missing Link towards Sustainable Consumption. Journal of Life Cycle Assessment, Japan, 4, 279-291. https://doi.org/10.3370/lca.4.279

[5] Saarinena, M., Kurppa, S., Virtanena, Y., Usvaa, K., Mäkeläb, J. and Nissinenc, A. (2012) Life Cycle Assessment Approach to the Impact of Home-Made, Ready-to-Eat and School Lunches on Climate and Eutrophication. Journal of Cleaner Production, 28, 177-186. https://doi.org/10.1016/j.jclepro.2011.11.038

[6] Tsuchiya, K. (2013) Learning on the Concept of Sustainability and LCA (Life Cycle Assessment): The Case of 21st Century Science. Environmental Education, 22, 30-36. https://doi.org/10.5647/jsoee.22.3_30

[7] Curran, M.A. (2015) Life Cycle Assessment Student Handbook. Willy, Hoboken, $320 \mathrm{p}$.

[8] Ramos, T.B., Caeiro, S., Hoof, B., Lozano, R., Huisingh, D. and Ceulemans, K. (2015) Experiences from the Implementation of Sustainable Development in Higher Education Institutions: Environmental Management for Sustainable Universities. Journal of Cleaner Production, 106, 3-10. https://doi.org/10.1016/j.jclepro.2015.05.110

[9] Uchida, A. and Fujilira, M. (2017) Comparison of Life Cycle $\mathrm{CO}_{2}$ between PET Bottle and Drink Carton: A Case Study Including Consumption of the Shopping Bag at J. F. Oberlin University. The Journal of J. F. Oberlin University. Natural and Applied Sciences, 8, 1-10.

[10] Kikuchi, Y. and Tsuji, K. (2017) A Chemical Risk Analysis for Research Activities in Universities Considering Local Risks and Environmental Impacts. Journal of Envi- 
ronment and Safety, 8, 1-14.

[11] Mori, K. and Hondo, H. (2018) Development of a Scale to Measure the "Sense of Link" Created by Life Cycle Thinking. Journal of Life Cycle Assessment, Japan, 14, 2-12. https://doi.org/10.3370/lca.14.2

[12] Goodall, S. (2018) Developing Environmental Education in the Curriculum. Routledge, Abingdon-on-Thames;, 144 p. https://doi.org/10.4324/9780429454578

[13] Poudelet, V., Chayer, J.A., Margni, M., Pellerin, R. and Samson, R. (2012) A Process-Based Approach to Operationalize Life Cycle Assessment through the Development of an Eco-Design Decision-Support System. Journal of Cleaner Production, 33, 192-201. https://doi.org/10.1016/j.jclepro.2012.04.005

[14] Hiyrayama, Y., Amano, Y., Ouchi, Y. and Hondo, H. (2015) Development and Implementation of Online Learning Program for Environmental Education Based on Life Cycle Thinking. Journal of Life Cycle Assessment, Japan, 14, 2-12.

[15] Kikuchi-Uehara, E., Hatanaka, S., Nakatani, J., Kikuchi, Y., Takaoka, Y. and Hirano, M. (2017) Development of Environmental Information Provision Approaches for Enhancing Consumers' Life Cycle Thinking Skills: Based on Scenario Analysis between Disposable and Reusable Shopping Bags. Journal of Life Cycle Assessment, Japan, 13, 332-348. https://doi.org/10.3370/lca.13.332

[16] Santosa O.S., Boticarioa, J.G. and Pérez-Marín, D. (2014) Extending Web-Based Educational Systems with Personalised Support through User Centred Designed Recommendations along the E-Learning Life Cycle. Science of Computer Programming, 88, 92-109. https://doi.org/10.1016/j.scico.2013.12.004

[17] Nakamura, A., Mizuno, T., Tsuda, S. and Itsubo, N. (2008) Quantitative Analysis on Practice and Effect of Environmental Education Adopting LCA. Proceeding of the 3th Annual Meeting of the Institute of Life Cycle Assessment, Nagoya, 28 February-March 1 in 2008, 305.

[18] Baboulet, O. and Lenzen, M. (2010) Evaluating the Environmental Performance of a University. Journal of Cleaner Production, 18, 1134-1141. https://doi.org/10.1016/j.jclepro.2010.04.006

[19] Nakajima, K., Hirayama, Y. and Hondo, H. (2011) Influences of Life Cycle Thinking-based Environmental Education Program on Pro-Environmental Behavior. Journal of Life Cycle Assessment, Japan, 7, 84-95. https://doi.org/10.3370/lca.7.84

[20] Imoto, R. and Semba, K. (2012) Alteration of Consciousness of University Students after Practical Work on a Farm: Significance of the Practical Work in Fostering of Home Economics Teachers. Research Abstracts on the Annual Meeting, Regular Meeting and Seminar of the Japan Association of Home Economics Education, Vol. $55,1$.

[21] Foo, K.Y. (2013) A Vision on the Role of Environmental Higher Education Contributing to the Sustainable Development in Malaysia. Journal of Cleaner Production, 61, 6-12. https://doi.org/10.1016/j.jclepro.2013.05.014

[22] Seo, M. (2015) Teaching Materials of "Impact of Clothing Life to the Environment" for Home Economics by Using Life Cycle Thinking: Towel as a Material. Research Abstracts on the Annual Meeting, Regular Meeting and Seminar of the Japan Association of Home Economics Education, Vol. 48, 68.

[23] Ueno, M., Ueda, S. and Seo, M. (2015) An Analytical Investigation of Descriptions of the Environment in Home Economics Textbooks: An Approach Based on Ideas of Life Cycle Assessment (LCA) and Life Cycle Thinking (LCT). Journal of Home Economics of Japan, 66, 39-53.

[24] NH Foods Ltd. (2016) Implementation of Life Cycle Assessment. 
https://www.nipponham.co.jp/csr/environment/climate/lca.html

[25] Miki, A., Nakatani, J. and Hirao, M. (2010) Scenario Analysis of Drinking Water Usage Applying Life Cycle Assessment for Consumers. Environmental Science, 23, 447-458. 